\title{
GEODIVERSIDADE E ANTROPOGEOMORFOLOGIA: POSSIBILIDADES PARA A CONSERVAÇÃO DO GEOPATRIMÔNIO EM ÁREAS DE MINERAÇÃO
}

\author{
Maurício Mendes Von Ahn \\ Universidade Federal de Pelotas, Pelotas, RS, Brasil \\ mauricio.von.ahn@gmail.com \\ Adriano Luís Heck Simon \\ Universidade Federal de Pelotas, Pelotas, RS, Brasil \\ adriano.simon@ufpel.edu.br
}

\begin{abstract}
RESUMO
Este artigo foi desenvolvido com o objetivo de analisar as possibilidades de inserção da abordagem antropogeomorfológica no estudo das formas do relevo associadas aos geossítios em áreas de mineração a céu aberto, a fim de subsidiar ações de geoconservação e promoção desse geopatrimônio. Foram analisados conceitos que colaboraram com as discussões sobre a conservação da natureza abiótica, seja ela natural ou antropogênica, bem como os reflexos imediatos sobre a biodiversidade. Ponderações sobre a possível relação da abordagem antropogeomorfológica com os princípios da geoconservação foram realizadas, considerando as áreas sob forte intervenção antropogênica, vinculadas às atividades de mineração a céu aberto. Conclui-se que é extremamente importante compreender a ação humana e a escala temporal de organização espacial das formas do relevo em geossítios situados em áreas de mineração a céu aberto. A herança deste processo de intervenção pode ser caracterizada a partir da análise antropogeomorfológica pautada na cartografia geomorfológica, que remete a todo um processo histórico de uso e ocupação pelas atividades de mineração e que podem ser interpretados cientificamente, pedagogicamente, culturalmente e economicamente por ações de geoturismo.
\end{abstract}

Palavras-chave: Geossítio. Geoconservação. Ação humana. Geomorfologia Antropogênica.

\section{GEODIVERSITY AND ANTHROPOGENIC GEOMORPHOLOGY: POSSIBILITIES FOR THE CONSERVATION OF THE GEOHERITAGE IN MINING AREAS}

\begin{abstract}
This article was carried out with the purpose of analyzing the possibilities of insertion of the anthropogeomorphological approach in the study of landforms associated to geosites in mining areas, in order to support geoconservation actions and the promotion of this geoheritage. Concepts which collaborated for the discussions on the conservation of abiotic nature, be it natural or anthropogenic, as well as the the immediate impacts on the biodiversity were analyzed. Considerations on the possible relationship of the anthropogeomorphological approach with the principles of geoconservation were weighted, considering the areas under strong anthropogenic intervention, linked to the mining activities. It is concluded that it is extremely important to understand the human action and the time scale of spatial organization of the landforms in geosites located in mining areas. The legacy of this intervention process may be characterized from the anthropogeomorphological analysis founded on the geomorphological cartography, which refers to a whole historical process of usage and occupation by the mining activities and that can be scientifically, pedagogically, culturally and economically interpreted by geotourism actions.
\end{abstract}

Keywords: Geosite. Geoconservation. Human Action. Anthropogenic Geomorphology.

\section{INTRODUÇÃO}

A geodiversidade abrange o conjunto de recursos geológico-geomorfológicos, seus fenômenos e processos ativos, incluindo suas relações, propriedades e sistemas que dão origem às paisagens

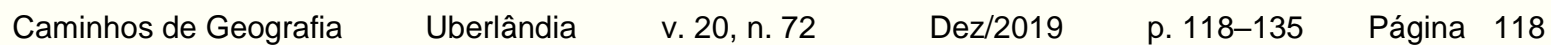


(STANLEY, 2000; NIETO, 2001; PROSSER, 2002; GRAY, 2004). Esse fato demonstra a representatividade que a geodiversidade possui no cenário de conservação da natureza, sendo considerada como o substrato para a sustentação da biodiversidade na Terra (BRILHA, 2005; PEREIRA, 2010).

As discussões sobre geodiversidade não são recentes na Ciência Geográfica, tendo sido realizadas por Troppmair (2000), referindo-se à geodiversidade como a multiplicidade de arranjos paisagísticos em determinada área/território. Segundo Troppmair e Galina (2006) a inexistência de uma paisagem igual à outra permite aos geógrafos a falarem em Geodiversidade da mesma forma como os biólogos falam em Biodiversidade.

Entretanto, o conceito de geodiversidade que se adota para a presente pesquisa possui forte vinculação com as proposições de Gray (2004, 2005 e 2008) e Brilha (2005) que, a partir do desenvolvimento de uma abordagem voltada para as geociências, definem que a geodiversidade abrange o conjunto de elementos abióticos terrestres, sendo que as diferentes articulações destes elementos podem levar à organização de locais com expressivo interesse científico, pedagógico, cultural, estético e turístico, que devem ser alvo de estratégias de geoconservação devido às suas particularidades geopatrimoniais.

O geopatrimônio consiste no conjunto dos geossítios e geomorfossítios (sítios de interesse geológicogeomorfológico), reconhecidos pelo conjunto de valores que representam à geodiversidade do território, englobando as formas do relevo e seus depósitos correlatos, os quais isoladamente ou em conjunto possuem significância para determinados processos morfogenéticos de uma dada região (VIEIRA e CUNHA, 2004; BRILHA, 2005; BORBA, 2011).

Considerando que o geopatrimônio, assim como os demais elementos da natureza abiótica e biótica, estão sujeitos a impactos e modificações naturais e antropogênicas, emerge, no final do século XX, a preocupação em assegurar a integridade dos elementos geológico-geomorfológicos que o compõe (PEREIRA, 2010). Brilha (2005) aponta que a atividade que tem como finalidade a conservação e gestão do geopatrimônio e dos processos naturais a ele associados intitula-se geoconservação, tendo este termo sido primeiramente definido por Sharples (2002, p.8) como a "conservação da geodiversidade por seus valores intrínsecos, ecológicos e geopatrimoniais".

Ainda são escassas as abordagens que consideram os patrimônios geomorfológico, paleontológico, mineralógico e hídrico no estudo da geodiversidade (PEREIRA et al., 2013a; PEREIRA et al., 2013b; SILVA et al., 2015) e ainda mais incipientes os estudos atrelados à geodiversidade que consideram enquanto geopatrimônio os elementos abióticos antropogênicos - formas criadas pelo Homem com significativa importância paisagística, científica, pedagógica, cultural e econômica. Nota-se que muitos estudos consideram as atividades antrópicas somente como uma ameaça ao geopatrimônio, e não como parte dele.

Verifica-se que existe um desconhecimento em relação aos aspectos e potenciais das formas do relevo de origem antropogênica enquanto geopatrimônio atrelado à geodiversidade. Isso faz com que a preocupação com a natureza seja focada quase que exclusivamente na conservação dos elementos abióticos naturais, sendo que a conservação dos elementos abióticos antropogênicos fique à margem desta temática.

O reconhecimento de geossítios no Brasil, realizado pela Comissão Brasileira dos Sítios Geológicos e Paleobiológicos (SIGEP) e a Companhia de Pesquisa de Recursos Minerais (CPRM), consideram os geossítios em áreas de mineração a céu aberto como representativos de um geopatrimônio antropogênico. Estes geossítios podem ter sua história evolutiva compreendida do ponto de vista da antropogeomorfologia, a qual possibilita a reconstrução do conjunto de técnicas e alterações na paisagem, desencadeadas para a constituição das antropoformas associadas a estes geossítios, realizando uma importante conexão entre geodiversidade e a ação das sociedades.

Neste sentido, o presente artigo foi desenvolvido com o objetivo de analisar as possibilidades de inserção da abordagem antropogeomorfológica no estudo e promoção das antropoformas associadas aos geossítios em áreas de mineração a céu aberto, a fim de subsidiar ações de geoconservação deste geopatrimônio.

\section{MATERIAL E MÉTODOS}

Para o desenvolvimento desta pesquisa foi realizado um levantamento e análise de referências bibliográficas para a identificação das possibilidades de articulação da abordagem antropogeomorfológica com os princípios da geoconservação, sobretudo em áreas fortemente

Caminhos de Geografia Uberlândia $\quad$ v. 20, n. $72 \quad$ Dez/2019 $\quad$ p. 119-136 Página 119


alteradas pelo Homem, mas que apresentam potencial para estudos e ações de caráter geoconservacionista. Para compreender 0 atual estado da arte dos geossítios em áreas de mineração, foram delimitados somente aqueles descritos e publicados pela CPRM (órgão oficial) e pela SIGEP (comissão científica específica para esse fim) e que estivessem dentro do contexto da mineração a céu aberto, seja em áreas de mineração ativas ou inativas. Apesar da existência de outros geossítios em áreas de mineração a céu aberto, reconhecidos por estudos independentes de pesquisadores em universidades ou outras instituições, neste artigo optou-se por apresentar os resultados daqueles reconhecidos por órgãos oficiais que trabalham com a temática.

Esta revisão de literaturas buscou suporte em livros, manuais técnicos, artigos científicos, dissertações de mestrado e teses de doutorado. A seleção das referências ocorreu em bases de dados online, tais como: Bibliotecas Digitais de universidades brasileiras e internacionais (Universidade Federal do Rio Grande do Sul, Universidade do Vale do Rio dos Sinos, Universidade de São Paulo, Universidade Estadual Paulista, Universidade Federal de Minas Gerais, Universidade Federal do Rio de Janeiro, Universidade do Minho, Universidade de Coimbra e Universidade do Porto); Biblioteca Digital Brasileira de Teses e Dissertações (BDTD); Google Acadêmico; International Association of Geomorphologists (IAG) - Geomorphosites e Landform Assessment for Geodiversity Working Groups, Portal de Periódicos CAPES/MEC; Comissão Brasileira de Sítios Geológicos e Paleobiológicos (SIGEP); International Union of Geological Sciences (IUGS); Global Indicative List of Geological Sites (GILGES); Serviço Geológico do Brasil (CPRM) e Scientific Eletronic Library Online (SCIELO).

A metodologia de busca das referências obedeceu a dois critérios e filtros, aplicados em todas as bases de dados online: palavras-chave e idioma. A definição de palavras-chave ocorreu a fim de identificar as comunidades de referência, as quais foram pensadas de forma a articular as temáticas antropogeomorfologia e geodiversidade, bem como mineração e geoconservação. Portanto, foram definidas 6 palavras-chave: geodiversidade; geoconservação; geopatrimônio; geossítos com ocorrência em áreas de mineração; geomorfologia antropogênica e cartografia geomorfológica. A busca das palavras-chave ocorreu de forma combinada, em inglês, português e espanhol, os quais são os idiomas de domínio do autor. A busca inicial levou à seleção de 128 referências bibliográficas, das quais 70 foram efetivamente selecionadas após a análise do resumo, objetivos e metodologia aplicada. O período de busca e revisão destas obras teve início em janeiro de 2015 e se estendeu até março de 2017.

\section{RESULTADOS E DISCUSSÃO}

Os resultados obtidos a partir dos procedimentos metodológicos descritos permitiram realizar algumas considerações acerca das possibilidades de integração do relevo antropogênico ao geopatrimônio, passível de ser analisado pela abordagem antropogeomorfológica, sobretudo em geossítios inseridos em áreas de mineração.

\section{Geodiversidade e suas possibilidades: uma abordagem a partir do geopatrimônio construído pela ação humana}

A conservação da natureza é uma temática amplamente difundida no mundo atual em consequência de uma série de fatores como a Revolução Industrial, os avanços tecnológicos, a expansão dos centros urbanos, o crescimento e adensamento populacional, a exploração de recursos minerais e fósseis e a deterioração da qualidade de vida dos seres humanos (PEREIRA, 2010). Brilha (2005) evidencia que diante da fragilidade dos recursos naturais e da degradação diretamente associada às necessidades de produção e consumo humano, faz-se necessário buscar o equilíbrio ambiental e promover o desenvolvimento sustentável, de forma a proteger esses recursos e garantir também a qualidade de vida.

Visando evitar uma maior degradação ambiental da Terra e diante da necessidade emergente de conservação e valorização dos componentes da geodiversidade, foram concebidos, na última década, os estudos vinculados à Geoconservação (SHARPLES, 2002; KOZLOWSKI, 2004; BRILHA, 2005; BRILHA e CARVALHO, 2010). No tocante às iniciativas de proteção da natureza, essa preocupação esteve por muitos anos focada nos elementos bióticos (biodiversidade), sendo que a

Caminhos de Geografia Uberlândia $\quad$ v. 20, n. $72 \quad$ Dez/2019 $\quad$ p. 119-136 Página 120


conservação do conjunto abiótico (geodiversidade), sempre esteve à margem desta temática (KOZLOWSKI, 2004; KOZLOWSKI et al., 2004a; BRILHA, 2005; GALUSZKA et al., 2009; PEREIRA, 2010).

A geodiversidade é o suporte para a sustentação dos ecossistemas e da biodiversidade, devendo ser considerada para fins de gestão, tomada de decisão, planejamento e educação (GRAY, 2004; BRILHA, 2005; GORDON, 2012). Sendo assim, há uma estreita relação entre a geodiversidade e a biodiversidade, uma vez que o desenvolvimento da vida e a possibilidade de apoiar o desenvolvimento sustentável está fortemente relacionada às condições abióticas, que têm sido a base para o aumento da diversidade biológica durante a histórica geológica da Terra (GRAY, 2004; KOZLOWSKI, 2004; BRILHA, 2005; PEREIRA, 2010).

Galuszka et al. (2009) e Kozlowski et al. (2004b) consideram que as pessoas geralmente acreditam que a biodiversidade deve ser mais protegida em função da sua maior fragilidade, pois não percebem as reais ameaças à geodiversidade. De acordo com Pemberton (2007) e Pereira (2010), as pessoas têm maior sensibilidade e interesse nas questões vinculadas à biodiversidade em detrimento dos componentes abióticos da natureza, inclusive fazendo com que as políticas públicas de conservação associem a proteção da natureza apenas à biodiversidade.

A sociedade atual se mostra distante de um maior entendimento sobre a importância que a geodiversidade possui no contexto geral da conservação e compreensão da evolução da natureza, bem como da existência de uma estreita relação entre a geodiversidade e a biodiversidade. Kozlowski et al. (2004a) ressaltam que os envolvidos nos estudos vinculados à proteção da geodiversidade devem sempre lembrar que a conservação dos elementos inanimados do ambiente está intimamente relacionada com a manutenção da biodiversidade, e somente tais ações podem servir para o bem da natureza e da criação de uma relação harmônica entre o Homem e o ambiente.

O conceito de geodiversidade é relativamente recente se comparado com demais conceitos da área de geociências (GRAY, 2008). Em meados da década de 1990, esse termo começa a aparecer na bibliografia européia, sobretudo em analogia ao termo biodiversidade (CARCAVILLA et al., 2008) que está restrito a diversidade biótica da natureza. Entretanto, ao contrário da geodiversidade, a biodiversidade se situa em patamar superior de reconhecimento e importância científica, política, econômica e ambiental, ao passo que as ações voltadas a geodiversidade e geoconservação começaram a despontar nos trabalhos acadêmicos e receber reconhecimento político somente na última década (MANOSSO, 2012).

Em contraste com a definição clara e precisa da biodiversidade, cujo conceito é baseado em níveis hierárquicos (genes, espécies e ecossistemas), a geodiversidade mostrou uma fragilidade conceitual importante, no sentido de que por muito tempo ficou restrita somente aos elementos e processos geológicos (SERRANO e RUIZ-FLAÑO, 2007), o que se tornou um problema na apropriação do conceito por parte das demais especialidades das geociências e de suas interfaces com as ciências humanas e biológicas (NAJWER e ZWOLINSKI, 2014). Desta forma, apesar do reconhecimento de uma definição, o termo é usado em diferentes significados e contextos (ZWOLINSKI, 2010).

Johansson et al. (1999), Nieto (2001) e Stanley (2001) definem geodiversidade de acordo com os fenômenos ou ambientes geológicos, entendendo a geodiversidade como um conceito integrador, porém restrito aos elementos e processos geológicos. Nieto (2001) define geodiversidade como o número e variedade de estruturas, formas e processos geológicos que constituem o substrato de uma região, sobre as quais se assenta a atividade orgânica, incluindo a antrópica. Estas duas visões iniciais apontam para a forte conexão do conceito de geodiversidade como sinônimo de diversidade geológica (SERRANO e RUIZ-FLAÑO, 2007).

Paralelamente ao desenvolvimento destes conceitos considerados restritivos no que se refere aos elementos e processos relacionados, visões mais amplas da geodiversidade foram propostas por Alexandrowicz (1999), Serrano (2002), Kozlowski (2004), Serrano e Ruiz-Flaño (2007), considerando não somente a diversidade geológica, mas também a variedade da natureza abiótica, seja ela natural ou antropogênica.

Para Serrano e Ruiz-Flaño (2007), a geodiversidade é definida pela variabilidade da natureza abiótica. Inclui os elementos litológicos, tectônicos, geomorfológicos, edáficos, hidrológicos,

Caminhos de Geografia Uberlândia $\quad$ v. 20, n. $72 \quad$ Dez/2019 $\quad$ p. 119-136 Página 121


topográficos e os processos físicos da superfície terrestre, mares, oceanos, junto aos processos naturais endógenos, exógenos e antrópicos que compreendem a diversidade de partículas, elementos e lugares.

De acordo com os referidos autores, a visão mais integradora é a de Kozlowski (2004, p.7), que define geodiversidade como "a variedade natural da superfície terrestre, incluindo os aspectos geológicos, geomorfológicos, solos, águas superficiais, bem como outros sistemas criados como resultados dos processos naturais endógenos e exógenos e a atividade humana".

Para Serrano e Ruiz Flaño (2007), a visão de geodiversidade proposta por Kozlowski (2004) cobre toda a variedade de partículas, elementos e sítios que materializam a variabilidade da natureza abiótica. A inclusão do termo "atividade humana" por Kozlowski (2004) poderia, segundo Borba (2011), ensejar uma indesejável superposição com o patrimônio cultural, construído pela humanidade. No entanto, embora isso possa ocorrer, compreende-se que os "(...) sistemas resultantes de (...) atividades humanas", para Kozlowski (2004), não seriam sítios culturais edificados pelo Homem, mas estariam muito mais atrelados às novas formas do relevo, resultantes da interferência humana como ação geomorfológica.

Aceitando-se a visão de Kozlowski (2004), entende-se que a geodiversidade deve ser definida e compreendida pelos elementos constitutivos do ambiente físico, sejam eles de origem natural ou antrópica, que dão origem às paisagens e que se relacionam de forma complexa com os elementos da biodiversidade. No entanto, observa-se que são escassas as abordagens que consideram os locais representativos de um patrimônio de origem antropogênica como áreas de interesse para estudos vinculados à geodiversidade.

Para López-García et al. (2011), áreas de mineração não são apenas locais onde as morfologias originais foram alteradas pelo Homem. De acordo com os autores, estas áreas possuem um papel fundamental, que é o de desvendar objetos geológicos e geomorfológicos que, sob condições naturais, seriam impossíveis de serem visualizadas. López-García et al. (2011) afirmam ainda que é possível considerar estes locais como um problema ou como uma oportunidade de compreender a magnitude da ação do Homem, pois nestas áreas ocorre o emprego de técnicas de alteração das feições geológico-geomorfológicas e a organização de paisagens que são reconhecidas enquanto parte da geodiversidade. Para isso, a identificação, caracterização e estudos de inventariação e gestão são necessários, bem como a relação destes estudos com uma abordagem que permita compreender as formas geradas pela ação humana enquanto componentes abióticos fortemente influenciados por técnicas e escalas de tempo históricas e não exclusivamente geológicas.

\section{Geoconservação no Brasil: iniciativas institucionais de valorização do geopatrimônio natural e antropogênico}

A sistematização das estratégias de geoconservação é recente no Brasil (década de 1990). No entanto, já é crescente o número de pesquisadores e espacialidades dedicados em estabelecer metodologias e abordagens de análise capazes de avaliar os elementos da geodiversidade e viabilizar a sua conservação (LIMA, 2008; BORBA, 2011; LOPES et al., 2011; NASCIMENTO et al., 2015).

De acordo com Von Ahn et al. (2016), no Brasil, considerando as unidades de conservação estabelecidas no Sistema Nacional de Unidades de Conservação (SNUC), é possível o enquadramento do geopatrimônio em apenas uma das categorias estabelecidas por esta Lei, definida pelos Monumentos Naturais. Entretanto, apesar do SNUC destacar a necessidade de proteção dos recursos abióticos nos seus objetivos, a partir da preservação de sítios naturais raros, singulares ou de grande beleza cênica, a lei ainda está essencialmente centrada na proteção dos recursos naturais bióticos, deixando os elementos abióticos sem o devido amparo legal.

O Projeto Sítios Geológicos e Paleobiológicos - SIGEP foi pioneiro nas atividades ligadas à geoconservação no Brasil, atuando na inventariação de sítios de interesse geológico-geomorfológico no âmbito nacional. O Brasil também apresenta o Programa de Geoparques Brasileiros baseado no programa Geoparks internacional, além de outros programas que se destacam pela promoção das 
geociências por meio da valorização e divulgação de sítios de interesse geológico, utilizando-se da ferramenta do geoturismo, como: Projeto Caminhos Geológicos do Rio de Janeiro, Projeto Sítios Geológicos e Paleontológicos do Paraná, Projeto Caminhos Geológicos da Bahia, Projeto Monumentos Geológicos do Rio Grande do Norte e Programa Geoecoturismo do Brasil.

O marco inicial de reconhecimento e geoconservação do geopatrimônio brasileiro é, sem dúvida, a Comissão da SIGEP - Sítios Geológicos e Paleontológicos do Brasil, criada no início de 1997, em resposta ao chamamento mundial feito em 1993 pelo Working Group on Geological and Palaeobiological Sites - GEOTOPES (NASCIMENTO, 2010). A principal atribuição da SIGEP era de selecionar os sítios geológicos brasileiros indicados anteriormente para a Global Indicative List of Geological Sites (GILGES) e para a Geosites Database da International Union of Geological Sciences (IUGS), apoiada no gerenciamento de um banco de dados nacional em atualização permanente e sua disponibilização em site da internet na forma de artigos científicos bilíngues elaborados por pesquisadores que trabalharam nas mais diferentes áreas dos sítios cadastrados (SIGEP, 2011; PEREIRA et al., 2008).

De acordo com Mansur et al. (2013), apesar do sucesso desta iniciativa, a SIGEP nunca foi oficializada legalmente no âmbito do Poder Público, não tendo autoridade para adotar ferramentas legais para a preservação dos geossítios. Assim, de acordo com a autora, em agosto de 2012, quinze anos depois de sua criação, a SIGEP suspendeu o recebimento de novas propostas de geossítios.

Entende-se que mesmo suspendendo o recebimento de novas propostas, a SIGEP coordenou e promoveu durante 15 anos ações pioneiras que refletiram os esforços em compreender a integração dos elementos bióticos e abióticos, em conjunto com a comunidade científica, possuindo um acervo riquíssimo no que diz respeito a propostas de geossítios, resumidos em: 116 geossítios publicados em 3 volumes e disponibilizados em PDF na internet; 51 geossítios aprovados, mas sem descrição disponível; 4 geossítios publicados em versão para leigos, e 26 sugestões preliminares de geossítios não formalizadas. Por isso, entende-se que os resultados obtidos durante este período devem ser valorizados e colocados frente a qualquer tipo de ação que venha a propor um amparo legal da legislação nacional.

O Projeto Geoparques é reconhecido pelo fato de suas intenções estarem voltadas ao planejamento e divulgação da geodiversidade nacional. Com o objetivo de apoiar cientificamente as propostas de criação dos geoparques no território brasileiro, o Serviço Geológico do Brasil (CPRM) estabeleceu, em 2006, o Projeto Geoparques no âmbito nacional, buscando identificar, classificar, descrever, catalogar, georreferenciar e divulgar os parques geológicos do Brasil, bem como definir diretrizes para seu desenvolvimento sustentável.

Este projeto vem sendo executado pelo Serviço Geológico do Brasil em parceria com universidades e órgãos ou entidades federais e estaduais, que tenham interesse em participar, e em harmonia com as comunidades locais. Além disso, desenvolve-se em sintonia com as atividades realizadas pelo SIGEP, entre outros projetos regionais (SCHOBBENHAUS, 2012).

De acordo com Mansur et al. (2013), as atividades do Projeto Geoparques abrangem o cadastramento e a quantificação de geossítios, contemplando as metodologias de Brilha (2005) e García-Cortés e Carcavilha (2009), adaptadas ao Brasil. A autora destaca que, independentemente das futuras ações a serem tomadas com relação aos propostos geoparques, o cadastramento dos geossítios realizado será incorporado em uma atividade mais ampla de âmbito nacional: o Inventário de Sítios do Patrimônio Geológico do Brasil.

\section{Ações do SIGEP e da CPRM nos geossítios em áreas de mineração}

López-García et al. (2011) argumentam sobre a possibilidade de minas abandonadas e/ou ativas serem elegíveis para algum tipo de proteção sob a égide da geoconservação. Para López-García et al. (2011), a mineração não pode ser vista somente como uma atividade vinculada à descaracterização de áreas naturais, uma vez que também permite uma visão mais abrangente de características geológicas, tais como: unidades de rocha, falhas, minerais, entre outros; os quais, sob circunstâncias normais, seriam impossíveis de serem visualizados e compreendidos (Figura 1). 
Figura 1 - Imagens dos distritos de Mazarrón e Cartagena (Espanha). A - Entrada principal do Geossítio de San Cristóbal, com destaque para a diversidade de cores dos depósitos de estéril; B Mina a céu aberto de Emila, onde é possível observar uma série de características geológicas locais.

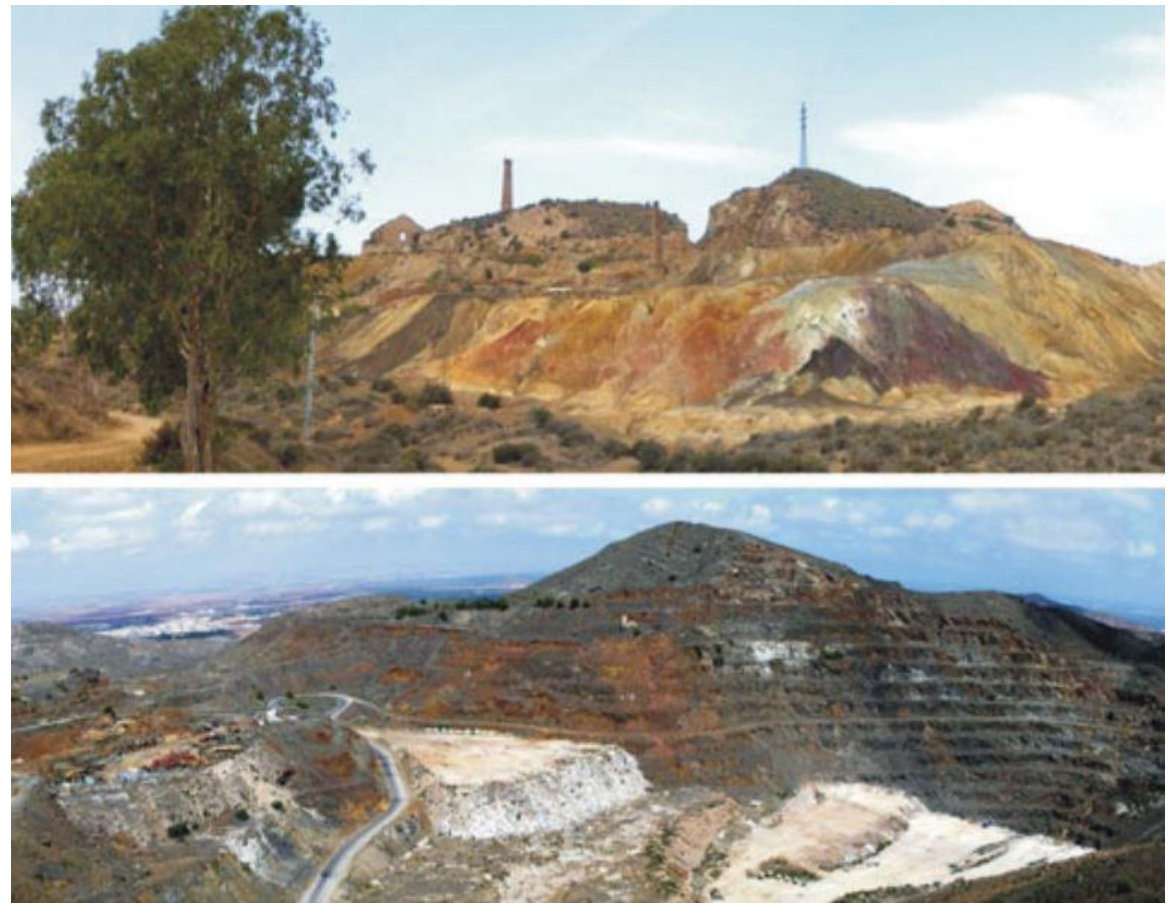

Fonte - López-García et al. (2011).

A exploração do relevo antropogênico em áreas de mineração já ocorre em locais como o Geossítio Minas do Camaquã (Rio Grande do Sul - Brasil) (Figura 2) a partir de atividades direcionadas para o turismo de aventura, tais como trilhas guiadas, tirolesa, remada, arvorismo, rapel, caiaque, caminhada, mountain bike e cicloturismo, quadriciclos, cavalgada, muro de escalada, entre outras (VON AHN e SIMON, 2019).

Figura 2 - Atividade de Stand Up Paddle realizada no lago situado em uma mina a céu aberto do Geossítio Minas do Camaquã - RS.

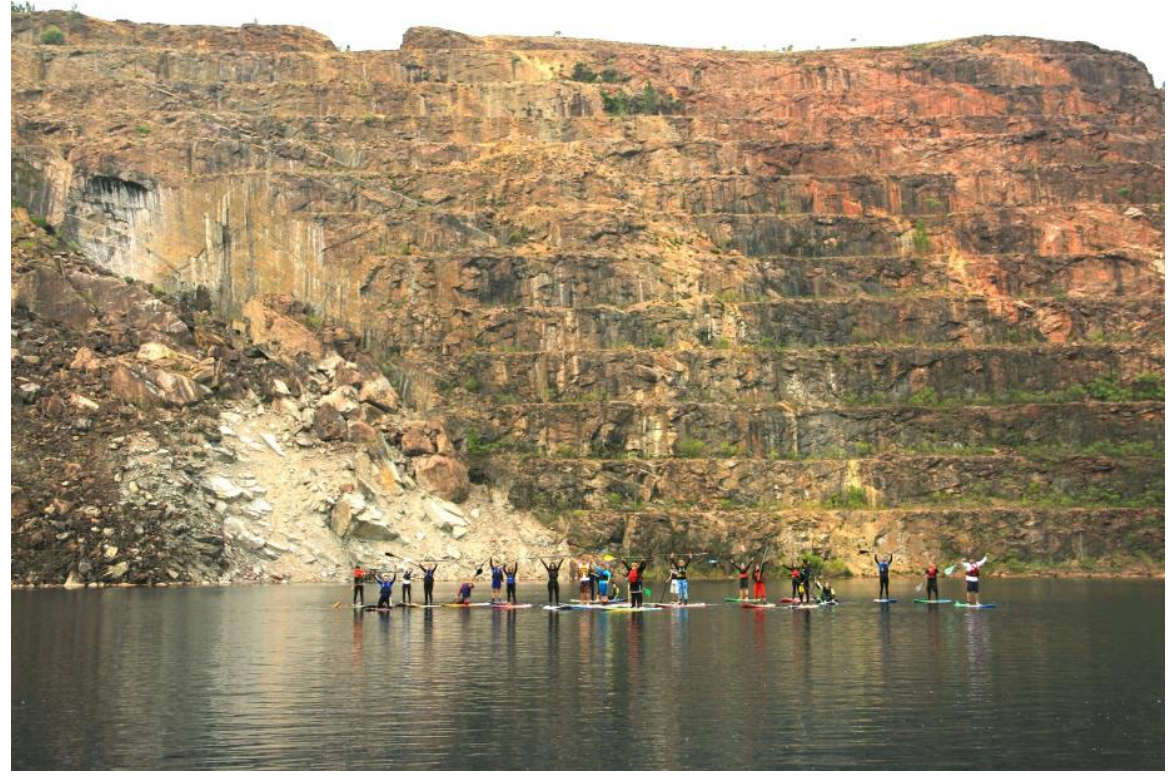

Foto - http://supclub.waves.com.br/sup/club/eventos/ii/encontro/das/remadas/mina/ceu/aberto. 
De acordo com López-García et al. (2011), desde que tenham suficiente valor educacional, cultural, histórico ou científico, estes locais devem ser reconhecidos a nível de geossítios. Apesar do significativo valor educativo de muitas minas antigas existentes, é difícil encontrar locais sob influência da mineração reconhecidos como geossítios.

As iniciativas de geoconservação no Brasil, realizadas pela SIGEP e CPRM, atuam no reconhecimento e inventariação de geossítios a partir da definição de tipologias, baseadas nas suas características e valor intrínseco para a geodiversidade. Determinadas tipologias e características de geossítios se aproximam das afirmações de López-García et al. (2011), uma vez que consideram locais representativos de um patrimônio antropogênico, caracterizados pelos geossítios em áreas de mineração, os quais estão vinculados a História da Mineração e da Geologia. No entanto, não existe uma abordagem que considere o relevo antropogênico destes locais enquanto elemento relevante do geopatrimônio, e os resquícios geomorfológicos oriundos do processo de extração mineral enquanto forte potencial para a promoção de regiões mineiras a partir de estratégias de geoconservação. A Tabela 1 evidencia os principais geossítios reconhecidos em território brasileiro e vinculados às atividades de mineração a céu aberto ativas ou inativas (Tabela 1).

Tabela 1 - Geossítios reconhecidos pela SIGEP e CPRM, inseridos em áreas de mineração a céu aberto (ativas ou inativas).

\begin{tabular}{|c|c|c|c|}
\hline GEOSSÍTIO & SITUAÇÃO & $\begin{array}{l}\text { INSTITUIÇÃO } \\
\text { PROPONENTE }\end{array}$ & $\begin{array}{c}\text { ESTADO } \\
\text { DA FEDERAÇÃO }\end{array}$ \\
\hline Lavra colonial Museu do Ouro & Inativa & \multirow{5}{*}{ CPRM } & \multirow{5}{*}{ Goiás } \\
\hline Cachoeira e lavra do Abade & Inativa & & \\
\hline Pedreira da prefeitura & Ativa & & \\
\hline Pedreira de quartzo Rosário & Ativa & & \\
\hline $\begin{array}{l}\text { Lavra colonial Encontro das } \\
\text { Águas }\end{array}$ & Inativa & & \\
\hline Pico de Itabira & \multirow[b]{2}{*}{ Inativa } & \multirow[b]{2}{*}{ SIGEP / CPRM } & \multirow{4}{*}{ Minas Gerais } \\
\hline $\begin{array}{l}\text { Conglomerado Diamantífero } \\
\text { Sopa }\end{array}$ & & & \\
\hline Mina do Córrego do meio & Inativa & \multirow[b]{2}{*}{ CPRM } & \\
\hline $\begin{array}{l}\text { Mina de Águas Claras } \\
\text { Capão do Lana }\end{array}$ & $\begin{array}{l}\text { Inativa } \\
\text { Inativa }\end{array}$ & & \\
\hline Mina Urucum - Vale & Ativa & \multirow{3}{*}{ CPRM } & \multirow{3}{*}{ Mato Grosso } \\
\hline Pedreira saladeiro & Ativa & & \\
\hline Mineração Horii & Ativa & & \\
\hline Pedreira quadrada & Inativa & CPRM & Rio Grande do Sul \\
\hline Morro pelado & Ativa & CPRM & $\begin{array}{l}\text { Rio Grande do Sul / } \\
\text { Santa Catarina }\end{array}$ \\
\hline Pedreira de ferro & Inativa & \multirow{3}{*}{ CPRM } & \multirow{3}{*}{ Paraná } \\
\hline Pedreira Fortaleza & Ativa & & \\
\hline Pedreira Malucelli & Inativa & & \\
\hline Banho de argila de Gaibu & Inativa & CPRM & \multirow{3}{*}{ Pernambuco } \\
\hline Pedreira Granito do Cabo & Inativa & SIGEP / CPRM & \\
\hline Ignimbrito Engenho Saco & Inativa & SIGEP / CPRM & \\
\hline Minas do Camaquã & Inativa & SIGEP / CPRM & Rio Grande do Sul \\
\hline $\begin{array}{l}\text { Cavas de ouro históricas do } \\
\text { Jaraguá }\end{array}$ & Inativa & SIGEP & São Paulo \\
\hline
\end{tabular}

Org - Elaborado pelos autores, 2018. 
Verifica-se, a partir da análise dos 23 geossítios em áreas de mineração (ativas e inativas) reconhecidos pela SIGEP e CPRM, que todos estão associados à interferência antropogênica nas formas do relevo, que atuam ou já atuaram para a consolidação de morfologias que não se desenvolveriam dentro de uma escala de tempo geológica e são resultantes de intervalos de tempo onde ocorre a dinamização das relações entre sociedade e natureza. A Figura 3 possibilita a visualização de alguns geossítios a partir dos exemplos listados na Tabela 1 que evidenciam morfologias antropogênicas associadas à extração de minério a céu aberto.

Figura 3 - Exemplos de Geossítios em áreas de mineração a céu aberto. A - Geossítio Pedreira Quadrada (RS); B - Geossítio Capão do Lana (MG); C - Geossítio Pedreira Malucelli (PR); D - Geossítio Pedreira Fortaleza (PR); E - Geossítio Ignimbrito Engenho Saco (PE); e F Geossítio Minas do Camaquã (RS).
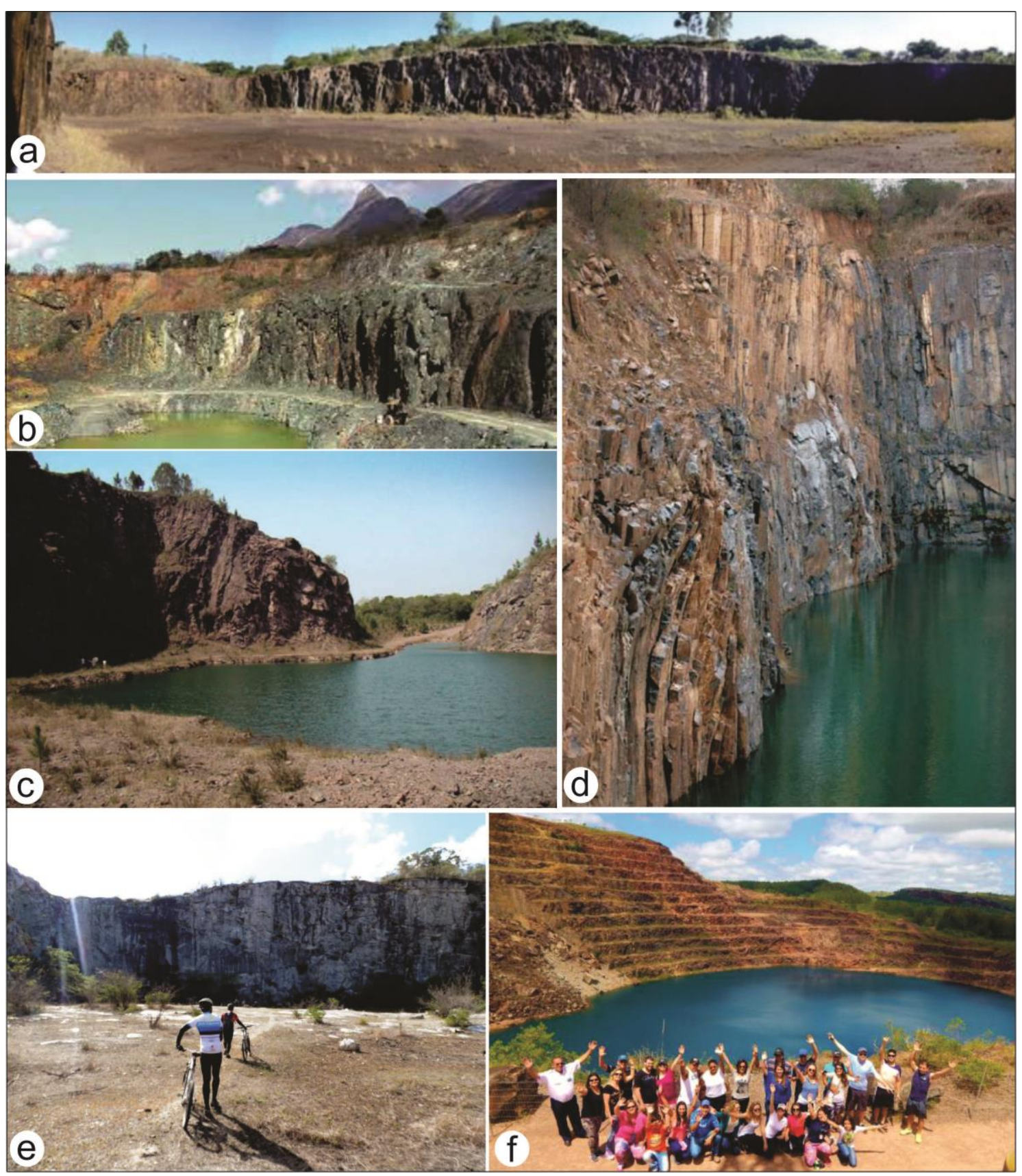

Org - Os autores. 
Percebe-se que, em alguns casos (Figura 3 - e, f), o relevo antropogênico dos geossítios já vem sendo utilizado para atividades turísticas e pedagógicas. As formas do relevo, apesar de derivadas de um processo intenso de exploração e descaraterização ambiental, possuem diferentes valores, os quais, nestes casos, já vem sendo compreendidos por turistas e estudantes do ensino universitário.

Estes geossítios possuem particularidades atreladas à ação humana na aplicação de técnicas e etapas complexas de intervenção para a constituição das formas do relevo, as quais, mesmo sendo resultantes de imposições antrópicas, possuem significados que conferem às mesmas 0 caráter de geopatrimônio. Assim como as formas de origem natural, atreladas à escala de tempo geológica, possibilitam importantes explicações sobre a história da Terra e os processos dinâmicos que atuaram para a configuração expressa na paisagem, as feições antropogênicas em áreas de mineração revelam importantes questões sobre a magnitude da intervenção tecnogênica, subsidiando explicações sobre a história da Terra em um período recente, onde se sobrepõem as escalas de tempo geológica e histórica (humana), na criação de formas e desenvolvimento de processos atrelados ao Tecnógeno.

O Tecnógeno é reconhecido por Peloggia (1997) como um período da história humana em que as alterações na paisagem passaram a ser mediadas pela técnica, equiparando-se aos outros agentes dos processos geológicos e geomorfológicos. É um termo que se articula à Geomorfologia e concentra-se no estudo dos produtos (depósitos e feições, ditos tecnogênicos) gerados diretamente ou influenciados pela atividade humana, e também de seus processos específicos, que atuam sobre os próprios depósitos tecnogênicos e relevos préexistentes (PELLOGIA, 1997).

Sharples (2002) sugere que os geossítios devem ser detentores de algum tipo de valor para os seres humanos, fornecendo evidências científicas do desenvolvimento passado da Terra, constituindo locais de importância para a investigação e educação, incluindo recursos de lazer ou turismo, e com características que formam a base de paisagens que têm contribuído para o sentido de lugar das comunidades humanas. Assim, considera-se que as formas de origem antropogênica presentes nos geossítios em áreas de mineração cumprem as condições propostas por Sharples (2002), e possibilitam ações de geoconservação pautadas na aplicação da abordagem antropogeomorfológica para a sua caracterização, valorização e promoção.

Estas ações podem estar atreladas aos estudos geográfico-geomorfológicos que compreendem que a ação humana é capaz de alterar de forma drástica as formas e processos naturais e que a eliminação dos esforços de alteração sobre estes elementos gera um conjunto de informações que ficam impressas na paisagem. De acordo com Gray (2005), essas informações devem ser aproveitadas para promover a maior relação entre a sociedade e os elementos da geodiversidade.

\section{Geomorfologia Antropogênica em geossítios inseridos em áreas de mineração}

Nas últimas décadas, os estudos geomorfológicos têm compreendido as intervenções humanas como ação geomorfológica independente (SZABÓ, 2010). Essas ações geram a alteração dos processos naturais, a partir de mecanismos de controle direto e/ou indireto, e consolidação de morfologias artificiais análogas à escala dos fenômenos que ocorrem no tempo geológico (DREW, 1989; RODRIGUES, 2005).

Por muito tempo, os estudos sobre a ação humana no equilíbrio e funcionamento dos sistemas geomorfológicos tiveram espaço coadjuvante nas pesquisas em geomorfologia (BROWN, 1971; 
GOUDIE, 1993). As formas do relevo e os processos modeladores eram compreendidos exclusivamente sob o ponto de vista da operação dos fatores naturais, desencadeados em uma escala de tempo geológica (BROWN, 1971; SUERTEGARAY e NUNES, 2001). Este posicionamento tradicional sofreu uma ruptura a partir das considerações propostas por Nir (1983), possibilitando a evolução de uma nova abordagem na geomorfologia: a geomorfologia antropogênica.

A geomorfologia antropogênica surge como termo alternativo à paisagem antropogênica (SOCTHAVA, 1977; PEREZ FILHO et al., 2001), e possui seus alicerces na perspectiva sistêmica (GOLOMB e EDER, 1964; GOUDIE, 1986, 1993; NIR, 1983; RODRIGUES, 1997, 2005; SZABÓ, 2010). Este viés destaca a concepção de que a humanidade, ao interferir de forma cada vez mais rápida e agressiva na dinâmica dos processos físico-ambientais, por meio de ações e incremento de técnicas de apropriação dos recursos naturais cada vez mais sofisticados e dinâmicos, passa da simples condição de agente dinamizador dos processos esculturadores do relevo para o de agente geomorfológico independente, capaz de criar novas formas de relevo e interferir nos processos geomorfológicos, guiados, sobretudo, por necessidades intrínsecas ao sistema socioeconômico em vigência (NIR, 1983; GOUDIE, 1993).

Nir (1983) é um dos primeiros pesquisadores a sugerir orientações metodológicas para as pesquisas desenvolvidas nesse âmbito, propondo que a análise antropogeomorfológica deva ocorrer de forma integrada, contemplando: (a) períodos pré e pós-significativas intervenções humanas; (b) a análise da dinâmica socioeconômica; e (c) a investigação dos ambientes antropogênicos a partir de estimativas quantitativas de extensão, taxas ou grau dos processos geomorfológicos observados. Ao integrar aspectos ambientais, socioeconômicos e físicos em sua metodologia, de maneira a contemplar acontecimentos ocorridos em um período de tempo histórico, Nir (1983) torna possível a realização de estudos inseridos na análise sistêmica.

A introdução, desenvolvimento e aplicação de uma metodologia para estudos em antropogeomorfologia no Brasil foi proposta por Rodrigues $(1997,2005)$, a partir de uma adaptação da proposta de Nir (1983), procurando identificar as características do meio físico em seus diversos estágios de intervenção antrópica: pré-perturbação, perturbação ativa e pósperturbação, com ênfase nos impactos ambientais e degradação dos sistemas físicoambientais causados pela ação humana.

Segundo Rodrigues (2005), as orientações básicas desta metodologia reforçam a necessidade de superar as abordagens com ênfase nos elementos exclusivamente definidos pela natureza e apontam à importância de tratamento simultâneo e sistemático das interferências antrópicas. Essas interferências são avaliadas enquanto ações geomorfológicas, podendo ser estudadas como intervenções nas formas, materiais e processos, tendo a cartografia geomorfológica como uma de suas principais metodologias de análise.

Rodrigues (2005, p. 101), recomenda que o mapeamento geomorfológico deva partir "[...] do reconhecimento cartográfico das unidades morfológicas originais para posteriormente considerar a sequência de intervenções antrópicas nas formas e na distribuição de materiais superficiais", os quais podem ser denominados de quadro de perturbação ativa ou de pósperturbação. Esta cartografia é denominada de "geocartografia geomorfológica retrospectiva" ou "evolutiva" e apoia-se no estudo sistemático morfológico, composto pelo tripé: materiais, formas e processos (HART, 1986 apud RODRIGUES, 2005).

No que se refere à concepção de morfologia original, Nir (1983) explica que ela é anterior a qualquer alteração promovida pela ação humana, enquanto Rodrigues (2005) admite que a morfologia original possa apresentar algumas modificações pouco expressivas no relevo, 
decorrentes do processo histórico de ocupação do espaço em análise. A fase de perturbação ativa ou de pós-perturbação retrata um cenário contrário ao anterior citado: nele, o Homem, ao desenvolver novas ferramentas e motivado pelos avanços tecnológicos e econômicos, intensifica sua intervenção sobre os aspectos físicos e promove modificações expressivas, que implicam em alteração nas dimensões de elementos passíveis de serem mensurados (NIR, 1983; RODRIGUES, 2005).

Investigações brasileiras e internacionais têm apresentado significativas contribuições acerca dos controles que o sistema socioeconômico causa sobre os atributos dos sistemas geomorfológicos. Grande parte destes estudos utiliza a cartografia geomorfológica como técnica aliada à compreensão das transformações no relevo. No entanto, verifica-se que estes estudos são pautados exclusivamente na análise de mudanças ambientais provocadas pela ação antrópica, sejam elas em áreas urbanas (RODRIGUES, 1997, 2005; PELOGGIA, 1997, 2005; PENTEADO e FUJIMOTO, 2006); em bacias hidrográficas, com ênfase em alterações em canais fluviais (RODRIGUES, 2006; SIMON e CUNHA, 2008; SIMON, 2010; PEREZ FILHO e QUARESMA, 2011); em áreas com alterações hidrogeomorfológicas atreladas aos usos da terra (JEAN-PIERRE, 2004; HOOKE, 2006).

Em áreas amplamente impactadas pela atividade minerária a abordagem antropogeomorfológica também tem sido utilizada na perspectiva de analisar as mudanças ambientais provocadas pela ação humana, e tem auxiliado a evidenciar os impactos da mineração, bem como subsidiar a recuperação e planejamento ambiental destas áreas (MARSH, 1865; SHERLOCK, 1922; LÓCZY e GYENIZSE, 2010; PASCHOAL, 2010, 2014; PASCHOAL et al., 2016).

Diante desta conjuntura apresentada, acredita-se que deva ocorrer o desenvolvimento de novas perspectivas no que se refere aos estudos da geomorfologia antropogênica: a interação/relação entre as formas de origem antrópica e o geopatrimônio, a fim de compreender e explicar a evolução das feições antropogênicas que podem ser aproveitadas geoturisticamente.

Entende-se que os geossítios reconhecidos em áreas de mineração são peculiares diante do contexto da geoconservação, pois, exclusivamente nesta tipologia, a ação antrópica atua diretamente na condição de agente geomorfológico. Estes geossítios também se tornam particulares do ponto de vista da antropogeomorfologia, pois, ao mesmo tempo em que a ação antrópica corrompeu o equilíbrio dinâmico destes sistemas, levando a uma nova configuração dos processos geológico-geomorfológicos, a herança deste processo de intervenção pode ser caracterizada e analisada para a promoção deste geopatrimônio, que remete a todo um processo histórico de uso e ocupação pelas atividades de mineração e que podem ser interpretados cientificamente, pedagogicamente, culturalmente e economicamente (a partir de atividades geoturísticas).

Deve-se considerar que, na atualidade, o que se encontra nestes geossítios são resquícios de um momento em que o Homem atuou (mineração inativa) ou continua atuando (mineração ativa) de forma muito intensa. Estas ações foram registradas a partir de um mapeamento geomorfológico retrospectivo realizado por Von Ahn (2018), que buscou registrar a história antropogeomorfológica do Geossítio Minas do Camaquã, evidenciando o conjunto de formas do relevo criadas pelo Homem em um pequeno intervalo de tempo (1977 - 2004) (Figura 4). Estas informações, registradas a partir da cartografia do relevo, podem fazer turistas, estudantes, cientistas, professores e a comunidade entender todo o processo de evolução das formas criadas pelo Homem a partir das técnicas empregadas. 
Figura 4 - Cavas de mineração a céu aberto inativas que compõem o Patrimônio Geomorfológico do Geossítio Minas do Camaquã - RS.

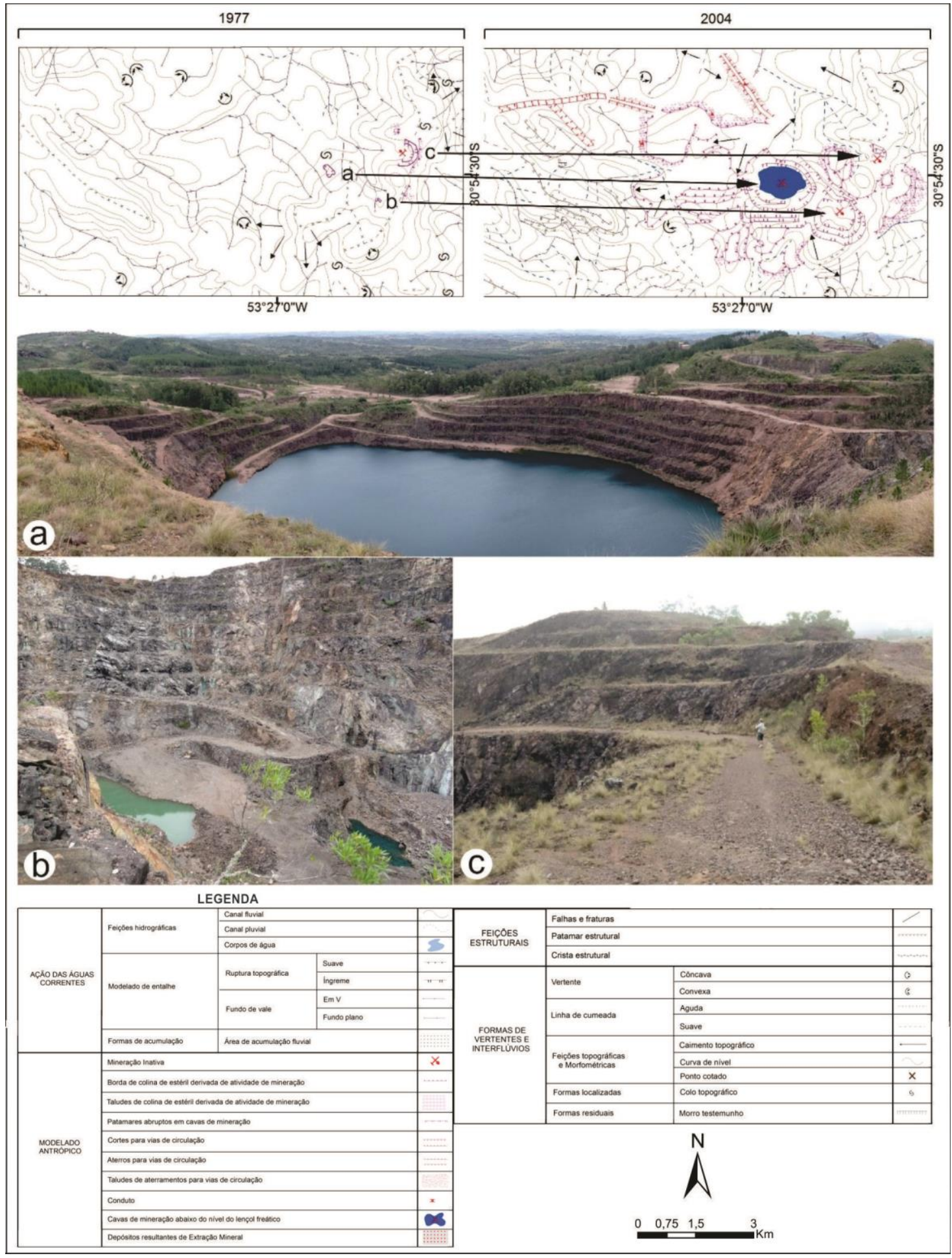

Fonte - Von Ahn (2018).

Em decorrência do avanço do processo de escavação a céu aberto, Von Ahn (2018) identificou, no ano de 2004, a organização de estágios mais desenvolvidos de morfologias que já existiam de forma incipiente no cenário de 1977. Em detrimento do abandono da atividade 
de extração mineral, duas minas a céu aberto atingiram o nível do lençol freático (Figura 4 - a, b).

Acredita-se que a utilização da cartografia geomorfológica associada às iniciativas e metodologias de conservação do patrimônio geológico-geomorfológico constituem uma ferramenta essencial para implementação da geoconservação, a partir da geração de documentos cartográficos que possam fomentar o aproveitamento da área para práticas pedagógicas, científicas, turísticas e culturais. Portanto, entende-se que os dados que contemplem cenários de pré-intervenção, intervenção ativa e pós-intervenções humanas fornecem subsídios para o desenvolvimento de futuras pesquisas relacionadas à temática da geoconservação, sobretudo no que tange a inventariação de geossítios com ocorrência em mineração, bem como a seleção de pontos de maior representatividade e interesse dos elementos geológico-geomorfológicos, de acordo com suas diferentes formas de aproveitamento.

\section{CONCLUSÃO}

Com base nas interpretações realizadas, considera-se importante relacionar a abordagem antropogeomorfológica com o geopatrimônio atrelado à mineração, uma vez que as formas do relevo de origem antrópica possuem um valor singular do ponto de vista histórico, didático, científico e turístico e devem ser exploradas em um viés diferenciado das paisagens onde ainda predominam as formas e processos naturais.

Isso poderia garantir o entendimento dos processos antrópicos que deram origem às feições antropogênicas e esclarecer a capacidade humana em gerar formas do relevo em uma escala de tempo histórica, de rápida ocorrência, desarticulando morfologias e processos que derivaram de uma escala temporal geológica.

A geoconservação deve ir além da conservação e valorização das formas naturais do relevo, uma vez que formas antropogênicas atuam no sentido de contar a história dos processos de mineração ativos e inativos, que contribuem para a formação territorial em escala nacional, regional e local e, portanto, possuem importância no que se refere à conjunção entre os elementos abióticos e socioeconômicos.

O aproveitamento do geopatrimônio antropogênico em áreas de mineração, principalmente para fins turísticos, históricos e didáticos, contribui para o incremento econômico local, sobretudo se as atividades de mineração foram suspensas e o principal vetor de desenvolvimento econômico não ocorre mais.

Desta forma, a proposta de roteiros geoturísticos voltados a contar a história destes geossítios e divulgar o seu geopatrimônio a partir da abordagem antropogeomorfológica seria uma proposta interessante a ser desenvolvida no que diz respeito à valorização e divulgação dos valores excepcionais presentes nos geossítios em áreas de mineração. Isso geraria também um envolvimento da população local, que possui conhecimento das etapas destas atividades e poderia auxiliar a ressaltar o aspecto histórico das feições que, embora antropogênicas, possuem singular aspecto estético e potencial para estudos científicos/pedagógicos.

\section{REFERÊNCIAS}

ALEXANDROWICZ, Z. Draft candidate list of geosites representative of Central Europe. Polish Geological Institute Special Papers, v. 2, p. 9-14, 1999.

BORBA, A. W. Geodiversidade e geopatrimônio como bases para estratégias de geoconservação: conceitos, abordagens, métodos de avaliação e aplicabilidade no contexto do Estado do Rio Grande do Sul. Pesquisa em Geociências, v. 38, p. 3-14, 2011. https://doi.org/10.22456/1807-9806.23832

BRILHA, J. Patrimônio Geológico e Geoconservação: a conservação da natureza em sua vertente Geológica. Braga: Palimage, 2005.

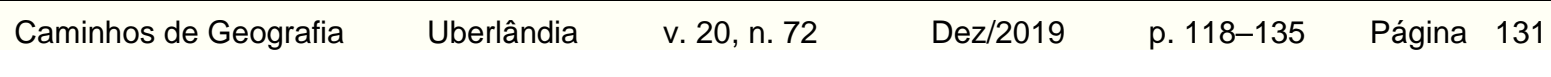


BRILHA, J.; CARVALHO, A. G. Ciências geológicas, Ensino, investigação e sua história, Geoconservação em Portugal: uma introdução. Associação Portuguesa de Geólogos, v. 2, p 435-441, 2010.

BROWN, E. H. O Homem modela a terra. Rio de Janeiro. Boletim Geográfico, v. 30, n. 222, p. 3-18, 1971.

CARCAVILLA, L.; DURÁN, J. J.; LÓPEZ-MARTINEZ, J. Geodiversidad: concepto y relación com el patrimonio geológico. In: Congreso Geológico de España, Las Palmas de Gran Canaria, p. 1299-1303, 2008.

DREW, D. Processos Interativos Homem-Meio Ambiente. Trad. SANTOS, J. A. do. Rio de Janeiro: Bertrand, 2. ed. 1989.

GALUSZKA, A.; MIGASZEWSKI, Z. M. Problemy zrówno ważone goużyt kowania surowców mineral nych (Problems of Sustainable Use of Mineral Resources). Problemy Ekorozwoju Problems of Sustainable Development, v. 4, n. 1, p. 123-130, 2009.

GARCÍA-CORTÉZ, A.; CARCAVILLA, L. U. Propuesta para la actualización metodológica del Inventario Español de Lugares de Interés Geológico (IELIG). Versión 11. 12-03-2009. Instituto Geológico y Minero de España, Madrid, 2009.

GOLOMB, B.; EDER, H. M. Lanforms made by man. Landscape, n. 14, p. 4-7, 1964.

GORDON, J. E. Rediscovering a Sense of Wonder: Geoheritage, Geotourism and Cultural Landscape Experiences, Geoheritage, v. 4, p. 65-77, 2012. https://doi.org/10.1007/s12371$\underline{011-0051-z}$

GOUDIE, A. The human impact on the natural environment. Cambridge: The MIT Press, 1986.

GOUDIE, A. Human influence in geomorphology. Geomorphology, v.7, p.37-59, 1993. https://doi.org/10.1016/B978-0-444-89971-2.50007-9

GRAY, M. Geodiversity: Valuing and Conserving Abiotic Nature. Chichester (U.K.): John Wiley \& Sons, 2004.

GRAY, M. Geodiversity \& Geoconservation, Geodiversity and Geoconservation: What, Why, and How?, London, v. 3, n. 3, p. 4-12, 2005.

GRAY, M. Geodiversity: A New Paradigm for Valuing and Conserving Geoheritage. Journal of Geological Association of Canada, v. 35, n. 2, p. 51-59, 2008.

HART, M.G. Geomorphology - pure and applied. London: Georqe Alen \&Unwin Ltd, 1986.

HOOKE, J. M. Human impacts on fluvial systems in the Mediterranean region.

Geomorphology, n. 79, p. 311-335, 2006. https://doi.org/10.1016/i.geomorph.2006.06.036

JEAN-PIERRE, L. Morphodynamique fluvial e actuelle d'origine anthropique: exemples danslebassin de la Loire (France). Géomorphologie: relief, processus, environnement, v. 2, n. 10, p. 127-138, 2004. https://doi.org/10.3406/morfo.2004.1209

JOHANSSON, C. E.; ANDERSEN, S. M. Geodiversity in the nordic countries. ProGeo News, v.1, p.1-3, 1999.

KOZLOWSKI, S. Geodiversity: the concept and scope of geodiversity. Przegląd Geologiczny, v.52, n.8, p.833-837, 2004.

KOZLOWSKI, S.; MIGASZEWSKI, Z.; GALUSZKA, A. Znaczenie georózno rodnosci w holistic znejwizji przyrody. Przegląd Geologiczny, v. 52, p. 291-294, 2004a.

KOZLOWSKI, S.; MIGASZEWSKI, Z.; GALUSZKA, A. Geodiversity conservation - conserving our geologic heritage. Polish Geological Institute Special Papers, v. 13, p. 13-20, 2004b

LIMA, F. F. Proposta metodológica para a inventariação do patrimônio geológico brasileiro. Dissertação (Mestrado em Patrimônio Geológico e Geoconservação) - Braga: Universidade do Minho, 2008. 
LÓCZY, D.; GYENIZSE, P. Human impact on topography in an urbanised mining area: Pécs, Southwest Hungary. Géomorphologie: relief, processus, environnement, v.3, p.287- 300, 2010. https://doi.org/10.4000/geomorphologie.7989

LOPES, L. S. O.; ARAÚJO, J. L. L. Princípios e estratégias de geoconservação. Revista Eletrônica de Geografia, v. 3, p. 66-78, 2011.

LÓPEZ-GARCÍA, J. A.; OYARZUN, R.; ANDRÉS, S. L.; MARTÍNEZ, J. I. M. Scientific, Educational, and Environmental Considerations Regarding Mine Sites and Geoheritage: A Perspective from SE Spain. Geoheritage, v. 3, p. 267-275, 2011.

https://doi.org/10.1007/s12371-011-0040-2

MANOSSO, F. C. Potencialidades da paisagem na Região da Serra do Cadeado-PR: abordagem metodológica das relações entre a estrutura geoecológica, a geodiversidade e o geoturismo. Tese (Doutorado em Geografia) - Maringá: Universidade Estadual de Maringá, 2012.

MANSUR, K.; ROCHA, A. J. D.; PEDREIRA, A.; SCHOBBENHAUS, C.; SALAMUNI, E.; ERTHAL, F. C.; PIEKARZ, G.; WINGE, M.; NASCIMENTO, M. A. L.; RIBEIRO, R. R. Iniciativas institucionais de valorização do patrimônio geológico do Brasil. Boletim Paranaense de Geociências, Curitiba, v. 70, p. 02-27, 2013. https://doi.org/10.5380/geo.v70i0.31729

MARSH, G. P. Man and nature: physical geography as modified by human action. New York: Charles Scribner, 1865. https://doi.org/10.5962/bhl.title.163042

NAJWER, A.; ZWOLIŃSKI, Z. B. Semantyka i metodykaoceny georóżn orodności - przegląd i propozy cjabadawcza. Landform Analysis, v. 26, p. 115-127, 2014. https://doi.org/10.12657/landfana.026.011

NASCIMENTO, M. A. L. Diferentes ações a favor do patrimônio geológico brasileiro. Estudos Geológicos, v. 20, n. 2, p. 81-92. 2010.

NASCIMENTO, M.; MANSUR, K. L.; MOREIRA, J. C. Bases conceituais para entender a Geodiversidade, Patrimônio Geológico, Geoconservação e Geoturismo. Revista Ecuador, v. 04, n. 03, 2015.

NIETO, L. M. Geodiversidad: propuesta de una definición integradora. Boletín Geológico y Minero, v. 112, p.3-11, 2001.

NIR, D. Man, a geomorphological agent. Jerusalém: Keter Publishing House, 1983. 165p.

PASCHOAL, L. G. Dinâmica do uso e ocupação da terra em área de mineração de argila: $\mathrm{O}$ caso da bacia hidrográfica do Ribeirão Santa Gertrudes/SP. Dissertação (Mestrado em Geografia) - Rio Claro: Universidade Estadual Paulista, 2010.

PASCHOAL, L. G. Estudo dos efeitos da criação de morfologias antropogênicas em área de mineração. Tese (Doutorado em Geografia) - Rio Claro: Universidade Estadual Paulista, 2014.

PASCHOAL, L. G.; RAMOS, A. M.; CUNHA, L. J. S.; CUNHA, C. M. L. Estudos geomorfológicos em área de mineração em Portugal: cartografia geomorfológica para análise do impacto sobre o relevo. Revista Brasileira de Geomorfologia, v. 17, n. 1, p. 61-78, 2016. https://doi.org/10.20502/rbg.v17i1.497

PELOGGIA, A. U. G. A ação do Homem enquanto ponto fundamental da geologia do

Tecnógeno: proposição teórica básica e discussão acerca do caso do município de São Paulo. Revista Brasileira de Geociências, v.27, n.3, p.37-44, 1997. https://doi.org/10.25249/0375$\underline{7536.1997257268}$

PELOGGIA, A. U. G. A cidade, as vertentes e as várzeas: a transformação do relevo pela ação do homem no município de São Paulo. Revista do Departamento de Geografia, v.16, p. 2431, 2005. https://doi.org/10.7154/RDG.2005.0016.0002

PEMBERTON, M. A. Brief Consideration of Geodiversity and Geoconservation.

Department of Primary Industries and Water, Tasmania, 2007. Disponível em: 
$<$ http://www.proceedings.com.au/quarrying2007/papers/paper_pemberton.pdf>. Acesso em: 25 de marco de 2016.

PENTEADO, A. F.; FUJIMOTO, N. S. V. Análise dos aspectos físicos e das intervenções antrópicas da bacia hidrográfica do Arroio Kruze - RS. Revista Eletrônica Geografar, v. 1, n. 1, p. 1-19, 2006. https://doi.org/10.5380/geografar.v111.6837

PEREIRA, R. F.; BRILHA, J.; MARTINEZ, J. E. Proposta de enquadramento da geoconservação na legislação ambiental brasileira. Revista Memórias e Notícias, Braga, n. 3, p. 491-494, 2008.

PEREIRA, R. G. F. A. Geoconservação e Desenvolvimento Sustentável na Chapada Diamantina (Bahia - Brasil). Tese (Doutorado em Patrimônio Geológico e Geoconservação) Braga: Escola de Ciências, Universidade do Minho, 2010.

PEREIRA, E. O.; AZEVEDO, U. R.; ONDICOL, R. P. Modelagem da geodiversidade na Área de Proteção Ambiental sul da região metropolitana de Belo Horizonte - MG. Geonomos, v. 21, n. 2, p. 97-101, 2013a. https://doi.org/10.18285/geonomos.v21i2.277

PEREIRA, D. I.; PEREIRA, P.; BRILHA, J.; SANTOS, L. Geodiversity Assessment of Paraná State (Brazil): Na Innovative Approach. Environmental Management, v. 52, p. 541-552, 2013b. https://doi.org/10.1007/s00267-013-0100-2

PEREZ FILHO, A.; SOARES, P. R. B.; ESPÍNDOLA, C. R. Processos erosivos e reativação de canais de drenagem no planalto ocidental paulista. In: Simpósio Nacional de Geografia Física Aplicada, 9, 2001, Recife. Anais... Recife: Universidade Federal de Pernambuco, 2001. v. 1. p. 84-85. https://doi.org/10.20502/rbg.v12i0.261

PEREZ FILHO, A.; QUARESMA, C. C. Ação antrópica sobre as escalas temporais dos fenômenos geomorfológicos. Revista Brasileira de Geomorfologia, v. 12, n. 3, p. 83- 90, 2011.

PROSSER, C. Terms of endearment. Earth Heritage, Gwynedd, n. 17, p. 12-13, 2002. Disponível em: <http://www.earthheritage.org.uk/ehpdf/EH17-2002.PDF>. Acesso em: 13 dez. 2016.

RODRIGUES, C. Geomorfologia Aplicada ao planejamento físico territorial brasileiro. Tese (Doutorado em Geografia Física) - São Paulo: FFLCH, USP, 1997.

RODRIGUES, C. Morfologia original e morfologia antropogênica na definição de unidades espaciais de Planejamento Urbano: exemplo da metrópole paulista. Revista do Departamento de Geografia, v.17, p.101-111, 2005. https://doi.org/10.7154/RDG.2005.0017.0008

RODRIGUES, T. R. I. Influência de reservatórios hidrelétricos na gênese e evolução da rede de drenagem no baixo curso do Rio São José dos Dourados. Tese (Doutorado em Geografia) - Campinas: Universidade Estadual de Campinas, 2006.

SCHOBBENHAUS, C.; SILVA, C. R. (Org.). Geoparques do Brasil - Propostas. Serviço Geológico do Brasil-CPRM, 2012, v. 1.

SHERLOCK, R. L. Man as a geological agent: an account of his action on inanimate nature. London: High Holborn, 1922.

SERRANO, E. Geomorphology, natural heritage and protected areas.Lines of research in Spain. In: CORATZA, P.; MARCHETTI, M. (eds.). Geomorphological sites: research, assessment and improvement - Workshop Proceedings, Modena: Universitä de glistudi de Modena, 2002. p. 27-33.

SERRANO, E.; RUIZ-FLAÑO, P. Geodiversity A theoretical and applied concept. Geographica Helvetica, v. 62, n. 3, p. 1-8, 2007. https://doi.org/10.5194/gh-62-140-2007

SHARPLES, C. Concepts and principles of geoconservation. PDF document, Tasmanian Parks and Wildlife Service, 2002. Website: www.parks.tas.gov.ua/tpws.html.

SIGEP (Comissão Brasileira de Sítios Geológicos e Paleobiológicos). Apresentação e formulário de proposta, 2011. Acesso em: sigep.cprm.gov.br. 
SILVA, P.; RODRIGUES, C.; PEREIRA, D. I. Mapping and Analysis of Geodiversity Indices in the Xingu River Basin, Amazonia, Brazil. Geoheritage, v. 7, p. 337-350, 2015. https://doi.org/10.1007/s12371-014-0134-8

SIMON, A. L. H.; CUNHA, C. M. L. Alterações geomorfológicas derivadas da intervenção de atividades antrópicas: Análise temporal na Bacia do Arroio Santa Bárbara - Pelotas (RS).

Revista Brasileira de Geomorfologia, v. 9, n. 2, p. 29-38, 2008. https://doi.org/10.20502/rbg.v9i2.107

SIMON, A. L. H. Influência do reservatório de Barra Bonita sobre a morfohidrografia da baixa bacia do Rio Piracicaba - SP: contribuições à geomorfologia antropogênica. Tese (Doutorado em Geografia) - Universidade Estadual Paulista, Rio Claro, 2010.

SOTCHAVA, V. B. O estudo de geossistemas. São Paulo, Instituto de Geografia, USP. 51p, 1977.

STANLEY, M. Geodiversity and why we need it. Earth Heritage, Gwynedd, n. 14, p. 15-18, 2000.

STANLEY, M. Geodiversity strategy - In: Progeo news. v. 1, p. 6-9, 2001.

SUERTEGARAY, D. M. A.; NUNES, J. O. R. A natureza da geografia física na geografia. São Paulo: Terra Livre, 2001.

SZABÓ, J. Anthropogenic Geomorphology: Subject and System. In: SZABÓ, J.; LÓRANT, D.; LÓCZY, D. Anthropogenic Geomorphology: a guide to man made landforms. London: Springer, 2010. https://doi.org/10.1007/978-90-481-3058-0

TROPPMAIR, H. Geossistemas e geossistemas paulistas. Rio Claro: Helmut Troppmair, 2000.

TROPPMAIR, H.; GALINA, M. H. Geossistemas. Mercator, v. 5, n. 10, p.79-89, 2006.

VIEIRA, A.; CUNHA, L. Patrimônio Geomorfológico: tentativa de sistematização. Actas do III Seminário Latino Americano de Geografia Física, Puerto Vallarta, México, 2004.

VON AHN, M. M.; SANTOS, F. C.; SIMON, A. L. H. Uso da terra, conflitos ambientais e a importância das relações entre geodiversidade e biodiversidade para a conservação da natureza. Geografia, Rio Claro, v. 1, n. 1, p. 131-146, 2016.

VON AHN, M. M. Análise Antropogeomorfológica em Geossítio da História da Mineração: estudo nas Minas do Camaquã - RS. Dissertação (Mestrado em Geografia) - Pelotas: Universidade Federal de Pelotas, 2018.

VON AHN, M .M.; SIMON, A. L. H. Abordagem geomorfológica no estudo do Patrimônio Mineiro. Mercator, v. 18, p. 1-10, 2019. https://doi.org/10.4215/rm2019.e18002

ZWOLINSK, Z. The routine of landform geodiversity map design for the Polish Carpathian Mts. Landform Analysis, v. 11, p. 77-85, 2010.

Recebido em: 25/05/2018

Aceito para publicação em: 26/11/2019 